Check for updates

Cite this: RSC Adv., 2021, 11, 16192

Received 14th March 2021

Accepted 20th April 2021

DOI: $10.1039 / \mathrm{d} 1 \mathrm{ra02025k}$

rsc.li/rsc-advances

\section{Thiosemicarbazone modified zeolitic imidazolate framework (TSC-ZIF) for mercury(II) removal from water}

\author{
Amani Jaafar, ${ }^{a}$ Carlos Platas-Iglesias (D) ${ }^{b}$ and Rana A. Bilbeisi (D) *a
}

Zeolitic imidazolate frameworks (ZIF-8), and their derivatives, have been drawing increasing attention due to their thermal and chemical stability. The remarkable stability of $\mathrm{ZIF}-8$ in aqueous and high $\mathrm{pH}$ environments renders it an ideal candidate for the removal of heavy metals from wastewater. In this study, we present the preparation of novel aldehyde-based zeolitic imidazolate frameworks (Ald-ZIF) through the integration of mixed-linkers: 2-methylimidazole (MIM) and imidazole-4-carbaldehyde (AldIM). The prepared Ald-ZIFs were post-synthetically modified with bisthiosemicarbazide (Bisthio) and thiosemicarbazide (Thio) groups, incorporating thiosemicarbazone (TSC) functionalities to the core of the framework. This modification results in the formation of TSC-functionalized ZIF derivatives (TSCZIFs). Thiosemicarbazones are versatile metal chelators, hence, adsorption properties of TSC-ZIFs for the removal of mercury(॥) from water were explored. Removal of mercury(॥) from homoionic aqueous solutions, binary and tertiary systems in competition with lead(॥) and cadmium(॥) under ambient conditions and neutral $\mathrm{pH}$ are reported in this study. $\mathrm{MIM}_{3.5}$ :Thio: $: \mathrm{Zn}$ improved the removal efficiency of mercury(॥) from water, up to $97 \%$ in two hours, with an adsorption capacity of $1667 \mathrm{mg} \mathrm{g}^{-1}$. Desorption of mercury(II) from MIM $_{3.5}:$ Thio $_{1}: Z n$ was achieved under acidic conditions, regenerating MIM $_{3.5}:$ Thio $_{1}: \mathrm{Zn}$ for five cycles of mercury(॥) removal. TSC-ZIF derivatives, designed and developed here, represent a new class of dynamically functionalized adsorption material displaying the advantages of simplicity, efficiency, and reusability.

\section{Introduction}

Metal-organic frameworks (MOFs) are a class of adsorbent materials composed of metal cations, connected to polytopic organic linkers via coordination bonds. $\mathrm{MOFs}^{1-3}$ as porous crystalline materials, combine high porosity, large surface area, flexible pore size and shape, ${ }^{4,5}$ and in most cases, a high stability, ${ }^{6}$ with simple, economical and convenient direct synthetic routes. ${ }^{7-9}$ The porous structure exhibited by MOFs offers large surface areas, reaching $\sim 5200 \mathrm{~m}^{2} \mathrm{~g}^{-1},^{10}$ and variety of pore dimensions and topologies. ${ }^{11}$ All the before mentioned properties render MOFs suitable candidates for catalysis, ${ }^{12-16}$ separation, ${ }^{17,18}$ gas storage, ${ }^{19-21}$ and drug delivery ${ }^{19,22-28}$ among other applications. ${ }^{16,29-32}$

\footnotetext{
${ }^{a}$ American University of Beirut (AUB), Department of Civil and Environmental Engineering, Riad El Solh, Beirut 1107-2020, Lebanon. E-mail: rb102@aub.edu.lb ${ }^{b}$ Centro de Investigacións Científicas Avanzadas (CICA) and Departamento de Quimica, Facultade de Ciencias, Universidade da Coruña, 15071 A Coruña, Galicia, Spain

$\dagger$ Electronic supplementary information (ESI) available: For general methods, supplementary details on the preparation and characterization of Ald-ZIFs and TSC-ZIFs, sorption isotherms and kinetics, and regeneration of the adsorbent. See DOI: $10.1039 / \mathrm{d} 1 \mathrm{ra02025 \textrm {k }}$
}

The flexibility of the coordination bond, joining the organic linker to metal ion, permits chemical modulations through post-synthetic modification (PSM) of the metal-organic framework. This promotes MOFs to high performance, tailor-made materials..$^{33}$ PSM, ranging from carrying out chemical transformation ${ }^{34-36}$ or exchange on pre-synthesized materials, ${ }^{37,38}$ has emerged as a powerful method for functionalizing MOFs. ${ }^{39,40}$

Zeolitic imidazolate frameworks (mainly, ZIF-8) received much attention due to their thermal and chemical stability which makes them ideal candidates for further adjustment of their physical and chemical features to attain satisfactory performances in a wide range of potential applications. ${ }^{41-43}$ ZIF8 structures have been prepared using different approaches, mainly hydro and solvothermal. ${ }^{44-46}$ The remarkable stability of ZIF-8 in aqueous and high pH environments renders it an ideal candidate for the removal of heavy metals from wastewater. ${ }^{47}$

Heavy metals, in general, are toxic to all living organisms. ${ }^{48}$ Mercury, in particular, is considered to be extremely dangerous due to high solubility and bioaccumulation properties. ${ }^{49,50}$ Different techniques have been developed for the removal of heavy metals from contaminated wastewater, ${ }^{51,52}$ such as chemical precipitation, ${ }^{53}$ membrane filtration, ${ }^{54}$ electrochemical treatments, ${ }^{55,56}$ adsorption ${ }^{57,58}$ and ion exchange. ${ }^{59,60}$ Removal of mercury cations from contaminated wastewater has 
been recently achieved using novel sulfur-functionalized MOFs ${ }^{61-63}$ adsorption parameters of these MOFs are presented in Table 1. Relevant parameters include maximum mercury adsorption capacity $\left(\mathrm{mg} \mathrm{g}^{-1}\right)$, retention time (minutes), and $\mathrm{pH}$ of the medium characterising HKUST- $1,{ }^{62}$ thiolfunctionalized ZIF-90 (ZIF-90-SH), ${ }^{64}$ UiO-66-NHC(S)NHMe, ${ }^{65}$ FJI-H12 ${ }^{66}$ and other robust MOFs ${ }^{67}$ are presented in the table. The most recent example of an efficient $\mathrm{Hg}$ (II) adsorption material is using hybrid material - ZnS with ZIF-8 on filter paper. The high sulfur content in the hybrid material exhibits outstanding adsorption of $\mathrm{Hg}$ (II), where the removal was achieved through simple filtration of contaminated water using the monolith ZnS-ZIF-8. ${ }^{68}$

This study presents the preparation of a new class of aldehyde modified ZIF-8 derivatives (Ald-ZIF), which were further functionalized with thiosemicarbazone (TSC) groups for the removal of mercury(II) ions from water. These Ald-ZIF were prepared through the integration of mixed-linkers: 2-methylimidazole (MIM) and imidazole-4-carbaldehyde (AldIM). The linkers were combined in two ratios $\left(x_{1}=15, y_{1}=1\right.$ and $x_{2}=$ $3.5, y_{2}=1$, where $x$ and $y$ represent the relative contents of MIM and AldIM, respectively) to yield two Ald-ZIF: MIM $_{15}:$ AldIM $_{1}: Z n$ and $\mathbf{M I M}_{3.5}:$ AldIM $_{\mathbf{1}}: \mathbf{Z n}$. The major component in all prepared Ald-ZIF is MIM, to retain the chemical and physical properties originally exhibited by ZIF-8. Incorporation of AldIM allows for further functionalization of the ZIF's framework, through postsynthetic modification (PSM). Accordingly, the prepared $\mathbf{M I M}_{x}: \mathbf{A l d I M}_{y}: \mathbf{Z n}$ were post-synthetically modified with two thiosemicarbazide based functionalities; bis $\left(\mathrm{NH}_{2}-\mathrm{NH}-\mathrm{CS}-\mathrm{NH}-\right.$ $\left.\mathrm{NH}_{2}\right)$ and thio $\left(\mathrm{NH}_{2}-\mathrm{NH}-\mathrm{CS}-\mathrm{NH}_{2}\right)$ semicarbazones, through the condensation of the aldehyde (in AldIM) to bis/ thiosemicarbazide. This successful PSM resulted in the formation of four new thiosemicarbazone zeolitic imidazole framework derivatives (TSC-ZIF), as demonstrated in Scheme 1.

\section{Results and discussion}

Aldehyde modified ZIF-8 (Ald-ZIF) derivatives were successfully prepared through modifying the synthetic procedure of ZIF-8. ${ }^{69}$ Simultaneous incorporation of commercially available 2-methylimidazole (MIM) and imidazole-4-carbaldehyde (AldIM) in two different ratios $\left(x_{1}=15, y_{1}=1\right.$ and $\left.x_{2}=3.5, y_{2}=1\right)$ yielded

Table 1 Comparison of maximum mercury(॥) adsorption capacity $q_{\max }\left(\mathrm{mg} \mathrm{g}^{-1}\right), \mathrm{pH}$, and adsorption time (min) of TSC-ZIF (MIM ${ }_{3.5}$ :$\mathrm{ThiO}_{1}: \mathrm{Zn}$ ) with previously reported sulfur-functionalized MOFs ${ }^{a}$

\begin{tabular}{|c|c|c|c|c|}
\hline MOF & $q_{\max }\left(\mathrm{mg} \mathrm{g}^{-1}\right)$ & $\mathrm{pH}$ & $t(\min )$ & Ref. \\
\hline Thiol-HKUST-1 & 714 & - & 120 & 62 \\
\hline ZIF-90-SH & 22 & - & 1440 & 64 \\
\hline UiO-66-NHC(S)R* & 769 & - & 240 & 65 \\
\hline FJI-H12 & 440 & 7 & 60 & 66 \\
\hline Zr-MSA & 734 & 5 & 5 & 67 \\
\hline ZnS-ZIF-8 & 925.9 & 5 & $<2$ & 68 \\
\hline MIM $_{3.5}:$ Thio $_{1}: Z n$ & 1667 & 7 & 30 & This study \\
\hline
\end{tabular}

${ }^{a} \mathrm{R}^{*}=\mathrm{NHCH}_{3}$.

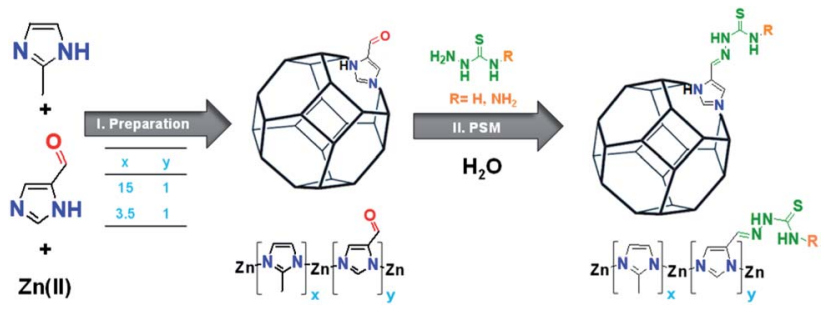

Scheme 1 Schematic illustration of (I) preparation of the two Ald-ZIFs $\left(\right.$ MIM $_{x}:$ AldIM $\left._{y}: Z n\right)$ and (II) post-synthetic modification (PSM) of AldZIFs to obtain TSC-ZIFs through the incorporation of thiosemicarbazone derivatives (bisthiosemicarbazone and/or thiosemicarbazone) in aqueous solution.

MIM $_{x}:$ AldIM $_{y}: Z n$ (please refer to the ESI†). MIM $_{15}:$ AldIM $_{1}: Z n$ was successfully prepared through hydrothermal conditions using $\mathrm{Zn}(\mathrm{OAc})_{2}$ in water/methanol at room temperature, whereas MIM $_{3.5}:$ AldIM $_{\mathbf{1}}: \mathbf{Z n}$ was only obtained under solvothermal conditions using $\mathrm{Zn}\left(\mathrm{NO}_{3}\right)_{2}$ in DMF at $110^{\circ} \mathrm{C}$ for $72 \mathrm{~h}$. Dynamic post-synthetic modification of MIM $_{15}:$ AldIM $_{\mathbf{1}}: \mathbf{Z n}$ and MIM $_{3.5}:$ AldIM $_{1}: Z n$ was performed on the aldehyde that condenses to the amine of the bisthiosemicarbazide (Bisthio, $\mathrm{R}$ $=-\mathrm{NH}_{2}$ ) or thiosemicarbazide (Thio, $\mathrm{R}=-\mathrm{H}$ ), yielding four novel TSC-ZIF: MIM 15 $_{\text {:Bisthio }}: Z n$, MIM $_{15}:$ Thio $_{1}: Z n$, MIM $_{3.5}$ :Bisthio $_{1}: \mathbf{Z n}$ and MIM $_{3.5}:$ Thio $_{1}: Z n$ (Scheme 1). The degree of functionalization of Ald-ZIFs was monitored by FTIR and NMR spectroscopies.

\section{Characterisation of Ald-ZIF and TSC-ZIF}

FTIR measurements. A band at $1690 \mathrm{~cm}^{-1}$ corresponding to the stretching $\nu(\mathrm{C}=\mathrm{O})$ vibration of the carbonyl group was observed in the IR spectra of $\mathbf{M I M}_{15}:$ AldIM $_{1}: \mathbf{Z n}$ and $\mathbf{M I M}_{3.5}$ :AldIM $_{\mathbf{1}}: \mathbf{Z n}$. This band disappears upon introducing the TSCfunctionalities, indicating successful post synthetic modification of Ald-ZIF. The conversion of the aldehyde groups, in AldZIFs, to imine groups in TSC-ZIFs, was further confirmed by the strong band at $1604 \mathrm{~cm}^{-1}$ corresponding to the $\mathrm{C}=\mathrm{N}$ stretching vibration. ${ }^{70}$ Two new IR bands are also observed at 1047 and (1864) $\mathrm{cm}^{-1}$, indicative of the presence of the thiosemicarbazone group corresponding to the $\nu(\mathrm{C}-\mathrm{N})$ and $\nu(\mathrm{C}=\mathrm{S})$ stretching vibrations, respectively (Fig. $\mathrm{S} 1$ in the ESI†े). Since the linker contains a thioamide $-\mathrm{NH}-\mathrm{C}=\mathrm{S}$ functional group, it can exhibit the thione-thiol tautomerism. ${ }^{71}$ The thiol $\nu(\mathrm{S}-\mathrm{H})$ band around $2570 \mathrm{~cm}^{-1}$ is absent from the IR spectra of the TSC-ZIFs, while the $\nu(\mathrm{N}-\mathrm{H})$ band is present at $3153 \mathrm{~cm}^{-1}$, indicating that, in the solid-state, the linker remains as the thione tautomer. The proposed IR assignments of the ZIFs are in good agreement with literature data. ${ }^{72-74}$ The introduction of the thioamide groups in $\mathbf{M I M}_{3.5}:$ Bisthio $_{1}: \mathbf{Z n}$ and $\mathbf{M I M}_{3.5}:$ Thio $_{1}: \mathbf{Z n}$ resulted in new vibrational bands, with characteristic absorptions at $2122 \mathrm{~cm}^{-1}$ corresponding to the $\nu_{\text {as }}(\mathrm{NH}-\mathrm{C}=\mathrm{S})$ modes. ${ }^{71}$

NMR analysis. The degree of functionalization of Ald-ZIFs and TSC-ZIFs was determined by digesting the ZIFs under acidic conditions. The imine bond (linking the AldIM and the bisthio/ thiosemicarbazide) does not get affected by the acidic conditions. This adopted method follows the general trend of 
cleaving MOFs, where the disassembly of the MOF takes place without cleaving the imine bond. ${ }^{75}$ Nuclear Magnetic Resonance (NMR) measurements were performed after digesting ZIF-8, Ald-ZIFs, and TSC-ZIFs in $80 \%$ deuterated solvent $\left(\right.$ DMSO- $\mathrm{d}_{6}$ or $\left.\mathrm{D}_{2} \mathrm{O}-\mathrm{d}_{2}\right)$ mixed with $20 \% \mathrm{~d}_{4}$-acetic acid $\left(\mathrm{CD}_{3}\right.$ COOD). The chemical shifts of both imidazole linkers, 2methylimidazole (MIM) and imidazole-4-carbaldehyde (AldIM), were referenced to DMSO-d $\mathrm{d}_{6}$ for $\mathbf{M I M}_{15}: \mathbf{A l d I M}_{1}: \mathbf{Z n}, \mathbf{M I M}_{15}$ :Bisthio $1: Z n$, and MIM $_{15}:$ Thio $_{1}: Z n$, whereas $\mathrm{D}_{2} \mathrm{O}-\mathrm{d}_{2}$ was used for referencing ZIF-8, MIM $_{3.5}$ :AldIM $\mathbf{A}: \mathbf{Z n}, \mathbf{M I M}_{3.5}:$ Bisthio $_{1}: \mathbf{Z n}$ and MIM $_{3.5}:$ Thio $_{1}: \mathbf{Z n}$ (see Fig. S2-S11†). The stoichiometry of the two imidazole linkers in the hybrid $\mathbf{M I M}_{\boldsymbol{x}}$ :AldIM $\mathbf{M}_{\boldsymbol{y}}: \mathbf{Z n}$ structures were determined by integrating the areas under the peak of the methyl protons of 2-methylimidazole and the aldehyde proton of imidazole-4-carbaldehyde $\left({ }^{1} \mathrm{H}\right.$ NMR spectra in Fig. S4 and $\mathrm{S} 7 \dagger$ ). The carbonyl resonance of the AldIM, was also apparent at 183 ppm in ${ }^{13} \mathrm{C}$ NMR of the digested $\mathbf{M I M}_{3.5}$ :AldIM $\mathbf{A}_{\mathbf{1}}: \mathbf{Z n}\left({ }^{13} \mathrm{C}\right.$ NMR spectra in Fig. S8†).

New sets of peaks were observed in the obtained NMR spectra of $\mathbf{M I M}_{\boldsymbol{x}}:$ Bisthio $_{\boldsymbol{y}}: \mathbf{Z n}$ and $\mathbf{M I M}_{\boldsymbol{x}}: \mathbf{T h i o}_{\boldsymbol{y}}: \mathbf{Z n}$; including a new peak in the aromatic range representative for the formation of the imine group $\mathrm{HC}=\mathrm{N}$, consistent with successful functionalization of the carbonyl group of AldIM with the bis/thiosemicarbazone groups. The ${ }^{1} \mathrm{H}$ NMR resonances of MIM $_{3.5}$ :Thio $:$ :Zn correspond to the imine proton at $8.1 \mathrm{ppm}$ and the three amine groups at 8.0, 7.4 and 7.9 ppm (see Fig. S10 $\dagger$ ). ${ }^{13} \mathrm{C}$ NMR spectra of MIM $_{3.5}:$ Bisthio $_{1}: Z n$ and MIM $_{3.5}:$ Thio $_{1}: Z n$ exhibit two peaks at 142.03 and $178.07 \mathrm{ppm}$ attributable to the $\mathrm{C}=\mathrm{N}$ and $\mathrm{C}=\mathrm{S}$ groups, respectively. The total transformation of the carbonyl groups in $\mathbf{M I M}_{\boldsymbol{x}}$ :AldIM $\boldsymbol{y}: \mathbf{Z n}$ to bis/ thiosemicarbazone groups was demonstrated by the absence of the aldehyde proton peak at 9.69 and 9.17 ppm, indicating a nearly complete conversion of post-synthetic modification. This was further confirmed by disappearance of the ${ }^{13} \mathrm{C}$ NMR peak at $183 \mathrm{ppm}$, corresponding to the carbonyl group of the parent MIM $_{3.5}:$ AldIM $_{1}: Z n$, in TSC-ZIFs (Fig. S9 and S11†).

Powder X-ray diffraction (PXRD) measurements. Crystallinity pattern and cubic framework structure of ZIF-8 was retained in Ald-ZIFs and TSC-ZIFs, as indicated by their PXRD diffraction data (the consistent peak positions and relative intensities as displayed in Fig. 1). ${ }^{12}$ The PXRD diffraction patterns of the hybrid Ald-ZIF and TSC-ZIF match the diffraction patterns of the single-linker ZIF-8 structures, with all ZIFs
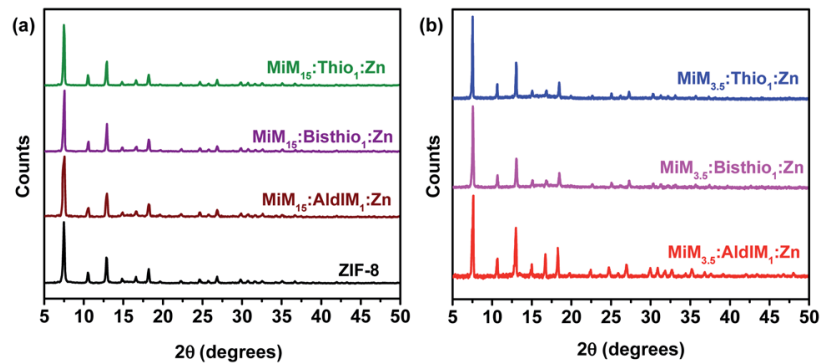

Fig. 1 PXRD pattern of the two ratios of: (a) MIM $_{15}:$ AldIM $_{1}: Z n$, (b) MIM $_{3.5}:$ AldIM $_{1}: Z n$. exhibiting virtually identical cubic unit cells. Furthermore, XRD details of the reported ZIFs indicate that all samples have relatively the same framework topology with small differences in electron density and lattice constant.

The prominent reflections at $2 \theta=7.4^{\circ}, 12.7^{\circ}$ and $18.0^{\circ}$ for the resulting ZIFs are clear, and are in good agreement with the simulated patterns for ZIF-8 using single crystal data (Fig. S12 $\dagger$ ), with a typical SOD structure. ${ }^{68}$

$\mathbf{N}_{2}$ sorption-desorption isotherm. The dinitrogen sorption isotherms of the Ald-ZIFs and TSC-ZIFs were measured at $77 \mathrm{~K}$, and the Brunauer-Emmett-Teller (BET) and pore volume of all the samples were calculated (Table 2 and Fig. S13 $\dagger$ ). ZIF samples were degassed overnight at $423 \mathrm{~K}$ before surface area determination. All ZIF samples, including the parent ZIF-8, were analysed using the same protocol since sorption behaviour for ZIFs is sensitive to handling and pre-treatment procedures.

As demonstrated in Table 2, the calculated BET surface area for ZIF-8 is $1555 \mathrm{~m}^{2} \mathrm{~g}^{-1}$, matching reported values in the literature $\left(1580 \mathrm{~m}^{2} \mathrm{~g}^{-1}\right)$. Given that the degree of post-synthetic modification and the size of the substituents dictate the available volume for the dinitrogen adsorption within the $\mathrm{ZIF},{ }^{37,76}$ we expected the BET surface area and pore volume to decrease in the mixed-linker ZIFs, relative to ZIF-8. Indeed, all the mixedlinker ZIFs exhibit lower surface areas, with the higher aldehyde incorporation $\left(\mathbf{M I M}_{3.5}\right.$ :AldIM $\left.\mathbf{M}_{\mathbf{1}}: \mathbf{Z n}\right)$ showing a more significant reduction in surface area than the lower aldehyde incorporation species ( $\left.\mathbf{M I M}_{\mathbf{1 5}}: \mathbf{A l d I M}_{\mathbf{1}}: \mathbf{Z n}\right)$. Thus, the BET surface area of MIM $_{15}$ :AldIM $\mathbf{1}: \mathbf{Z n}$ was found to be $1397 \mathrm{~m}^{2} \mathrm{~g}^{-1}$, marginally lower than that of ZIF-8. Whereas, the surface area of MIM $_{15}:$ Bisthio $_{1}: \mathbf{Z n}$ and $\mathbf{M I M}_{15}:$ Thio $_{1}: \mathbf{Z n}$ is reduced relative to that of MIM $_{15}:$ AldIM $_{\mathbf{1}}: \mathbf{Z n}$ due to the decrease of internal void space associated with the introduction of the carbonyl groups. Similarly, post-synthetic modification of $\mathbf{M I M}_{3.5}: \mathbf{A l d I M}_{1}: \mathbf{Z n}$ results in a more significant decrease in BET surface area to 623 and $679 \mathrm{~m}^{2} \mathrm{~g}^{-1}$ for MIM $_{3.5}$ :Bisthio $:$ :Zn and MIM $_{3.5}:$ Thio $_{1}: \mathbf{Z n}$, respectively. This can be attributed to the higher degree of modification with bisthiosemicarbazone and thiosemicarbazone groups.

SEM-EDX measurements. Surface morphology and chemical composition of Ald-ZIFs and TSC-ZIFs were also investigated using SEM (Fig. 2) and EDX (Fig. S14 $\dagger$ ). The crystals of original ZIF-8 and MIM $_{15}:$ AldIM $_{1}: \mathbf{Z n}$ present cubic and rhombic

Table 2 Textural parameters and the yields of the ZIF-8, Ald-ZIFs and the TSC-ZIFs

\begin{tabular}{|c|c|c|c|}
\hline Sample & $S_{\mathrm{BET}}{ }^{a}\left(\mathrm{~m}^{2} \mathrm{~g}^{-1}\right)$ & $V_{\text {micro }}^{b}\left(\mathrm{~cm}^{3} \mathrm{~g}^{-1}\right)$ & Yield (\%) \\
\hline ZIF-8 & 1555 & 0.73 & 93 \\
\hline MIM $_{15}:$ AldIM $_{1}: Z n$ & 1396 & 0.63 & 75 \\
\hline MIM $_{15}:$ Bisthio $_{1}: Z n$ & 1128 & 0.5 & 40 \\
\hline MIM $_{15}:$ Thio $_{1}: Z n$ & 1237 & 0.58 & 77 \\
\hline MIM $_{3.5}:$ AldIM $_{1}: Z n$ & 1130 & 0.37 & 54 \\
\hline MIM $_{3.5}:$ Bisthio $_{1}: \mathbf{Z n}$ & 623 & 0.20 & 57 \\
\hline MIM $_{3.5}:$ Thio $_{1}: Z n$ & 679 & 0.26 & 62 \\
\hline
\end{tabular}

${ }^{a} S_{\mathrm{BET}}$ is the BET surface area. ${ }^{b} V_{\text {micro }}$ is the $t$-plot micropore volume. 

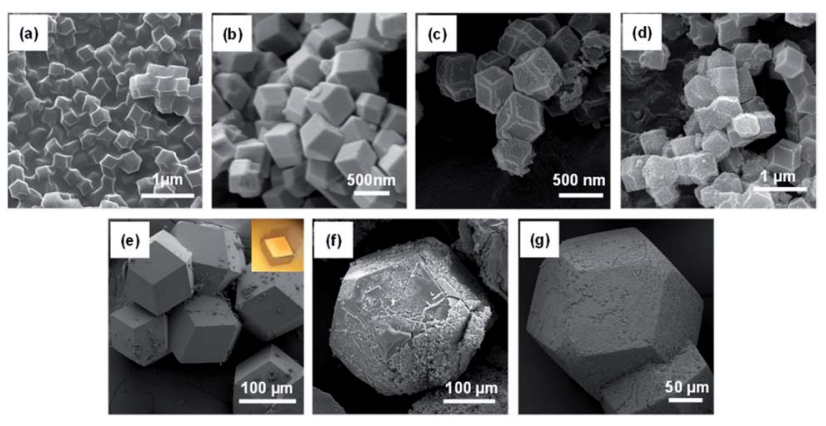

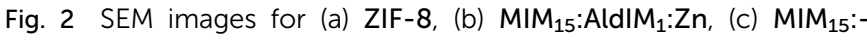
Bisthio $1: Z n,(d)$ MIM $_{15}:$ Thio $_{1}: Z n$, (e) MIM M $_{3.5}:$ AldIM $_{1}: Z n$ (inset: crystals of MIM $_{3.5}:$ AldIM $_{1}: Z n$ ), (f) MIM $_{3.5}:$ Bisthio $1: Z n$ and (g) MIM $3.5:$ Thio $:$ :Zn.

dodecahedral shapes, respectively. Both exhibited smooth surfaces, and an average size of $500 \mathrm{~nm}$. However, the surfaces of the $\mathbf{M I M}_{15}:$ Bisthio $_{1}: \mathbf{Z n}$ sample experience a significant morphological change, as the shape changed from a rhombic dodecahedron with smooth faces and sharp edges in $\mathbf{M I M}_{\mathbf{1 5}}$ :AldIM $_{1}: Z n$, to truncated-edge rhombic dodecahedra for MIM $_{15}:$ Bisthio $_{1}: \mathbf{Z n}$, but the size of the particles does not change significantly $(\sim 500 \mathrm{~nm})$. The crystals of $\mathbf{M I M}_{15}: \mathbf{T h i o}_{\mathbf{1}}: \mathbf{Z n}$ are rhombic dodecahedra with a bumbled surface due to the substitution of thiosemicarbazone. The crystals of $\mathbf{M I M}_{3.5}$ :AldIM $_{1}: Z n, \quad$ MIM $_{3.5}:$ Bisthio $_{1}: Z n$ and MIM $_{3.5}:$ Thio $_{1}: Z n$ are rhombic dodecahedral with different aspects, smooth on the surface and a large size up to $100 \mu \mathrm{m}$ (Fig. 2).

The EDX spectra of the TSC-functionalized ZIFs confirmed that the ZIF samples are composed of $\mathrm{C}, \mathrm{N}, \mathrm{O}, \mathrm{Zn}$, and $\mathrm{S}$, as presented in Fig. S14. $\dagger$ The relative content of $S$ in the functionalized TSC-ZIFs were determined by EDX spectra.

TGAs curves analysis. Thermal stability of the prepared AldZIF and TSC-ZIF samples, relative to ZIF-8, was characterised by thermal gravimetric analysis, (TGA) (Fig. S15†). Prepared AldZIFs and TSC-ZIFs display relatively high thermal stability similar to that of ZIF-8. MIM $_{3.5}$ :AldIM $\mathbf{A}: \mathbf{Z n}$ undergoes an initial weight loss at about $450{ }^{\circ} \mathrm{C}$, which can be attributed to the loss of carbonyl groups of the framework. A further weight loss at $550{ }^{\circ} \mathrm{C}$ is observed for ZIF-8 and MIM $_{3.5}:$ AldIM $_{1}: \mathbf{Z n}$ due to framework decomposition. $\mathbf{M I M}_{3.5}:$ Bithio $_{1}: \mathbf{Z n}$ and $\mathbf{M I M}_{3.5}$ :Thio $_{1}: \mathbf{Z n}$ undergo weight loss at around $220{ }^{\circ} \mathrm{C}$, which is not present in the ZIF-8 and Ald-ZIF samples. This can be attributed to the decomposition of the bisthiosemicarbazone and thiosemicarbazone groups, respectively. However, $\mathbf{M I M}_{\mathbf{1 5}^{-}}$ : Bithio $_{1}: \mathbf{Z n}$ and $\mathbf{M I M}_{15}$ :Thio $\mathbf{T}_{\mathbf{1}}: \mathbf{Z n}$ exhibit negligible percentage weight loss at this temperature due to the low percentage of the TSC-linker within the framework of the ZIF.

DFT calculations. X-ray diffraction studies show that the incorporation of imidazole-4-carbaldehyde to the framework of ZIF-8 does not alter significantly the structure of the ZIF. To get insight into the orientation of the imidazole-4-carbaldehyde (AldIM) and thiosemicarbazone group (Thio) within the structure of the ZIF, we performed DFT calculations at the b3lyp/6$31 \mathrm{G}(\mathrm{d}, \mathrm{p})$ level. ${ }^{77-79}$ The X-ray crystal structure of ZIF-8 was truncated to include $24 \mathrm{Zn}$ (II) ions that define the large cage of the structure, with 8 of the 60 2-methylimidazole (MIM) (supposed to be 1 to 3.5) groups being replaced by imidazole-4carbaldehyde. These calculations yielded the expected tetrahedral coordination of the $\mathrm{Zn}$ ions provided by the bridging imidazole groups, with $\mathrm{Zn}-\mathrm{N}$ distances of $2.0-2.04 \AA$ (1.97 $\AA$ in the X-ray structure).$^{80}$ Our DFT studies suggest that the carbaldehyde groups point inwards the six-membered hexagonal $\mathrm{Zn}$ rings, with the $\mathrm{O}$ atom being placed slightly below the mean plane defined by the six $\mathrm{Zn}$ ions (ca. $0.78 \AA$, Fig. 3). Indeed, changing the orientation of one of the aldehyde groups of this model towards one of the pores, defined by four $\mathrm{ZnN}_{4}$ tetrahedra, results in a significant increase in energy of $7.8 \mathrm{~kJ} \mathrm{~mol}^{-1}$. Subsequent calculations on the same model where two imidazole-4-carbaldehyde groups are replaced by thiosemicarbazone units suggest that the bulky thiosemicarbazone groups are also directed towards the large central pores of the structure.

\section{Mercury(II) removal efficiency from water}

The ability of the Ald-ZIF and TSC-ZIF derivatives to sequester mercury(II) from aqueous solutions was investigated at ambient conditions (room temperature and neutral $\mathrm{pH}$ ). Adsorption studies were conducted over a wide range of known mercury concentrations (ppm), with the change in the adsorbent colour (yellow crystals in the case of $\mathbf{M I M}_{3.5}:$ Thio $_{1}: \mathbf{Z n}$ ) to black at high mercury(II) concentrations serving as a preliminary indication of adsorption (Fig. S16†).

Equations eqn (S1) and (S2) † were used to calculate the metal removal (\%) from an aqueous solution where $C_{\mathrm{i}}$ and $C_{\mathrm{e}}$ represent the initial and equilibrium metal ion concentrations ( $\mathrm{mg}$ $\mathrm{L}^{-1}$ ), respectively. The results for treating $\mathrm{Hg}$ (II) solutions with ZIF-8, Ald-ZIF and TSC-ZIF derivatives are presented in Fig. 4(a) and $\mathrm{S} 17 . \dagger$ Treatment of a $100 \mathrm{mg} \mathrm{L}^{-1}$ aqueous $\mathrm{Hg}$ (II) solution with MIM $_{15}:$ Thio $_{1}: Z n$ and MIM $_{15}:$ Bithio $_{1}: Z n$ led to a $92.0 \%$ and 91.8\% reduction in $\mathrm{Hg}$ (II) content within $30 \mathrm{~min}$ at ambient conditions. However, treating a $\mathrm{Hg}$ (II) solution of the same concentration, and under the same conditions, with ZIF-8 and MIM $_{15}:$ AldIM $_{1}: \mathbf{Z n}$ resulted in $15 \%$ and $12 \%$ reduction, respectively (Fig. S17 $\dagger$ ). An obvious increase in the adsorptive removal of mercury cation was observed in TSC-ZIFs incorporating a higher degree of functionality (ratio $X_{2}=3.5: y_{2}=1$ ). Indeed,

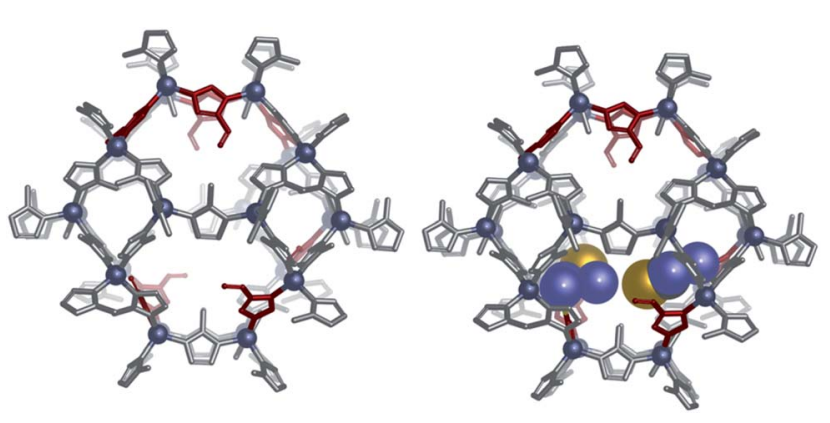

Fig. 3 Models of the ZIF-8 structure incorporating (I) imidazole-4carbaldehyde Ald-ZIF (left) and (II) imidazole-4-carbaldehyde and thiosemicarbazone TSC-ZIF (right) groups, optimized at the b3lyp/6$31 \mathrm{G}(\mathrm{d}, \mathrm{p})$ level. 

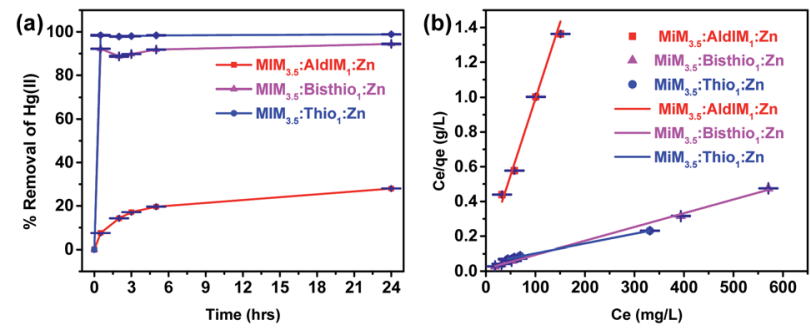

Fig. 4 (a) Percentage removal of $[\mathrm{Hg}(\mathrm{II})]$ with time using $\mathrm{MIM}_{3.5}$ :AldIM $1: Z n, \quad$ MIM $_{35}:$ Bisthio $_{1}: Z n$ and MIM $_{3.5}:$ Thio $_{1}: Z n \quad([\mathrm{Hg}(॥)]=$ $400 \mathrm{mg} \mathrm{L}^{-1}$ ), (b) Langmuir equation fitting curve for the adsorption isotherms for the MIM $_{3.5}:$ AldIM $_{1}: Z n$, MIM $_{3.5}:$ Bisthio $_{1}: Z n$ and MIM $_{3.5}:$ Thio $_{1}: \mathrm{Zn}$.

the treatment of a $\mathrm{Hg}$ (II) solution $\left(C_{\mathrm{i}}=400 \mathrm{mg} \mathrm{g}^{-1}\right)$ with MIM $_{3.5}:$ Thio $_{1}: \mathbf{Z n}$ and MIM $_{3.5}:$ Bithio $_{1}: Z n$ resulted in $98.9 \%$ and 94.4\% removal of the $\mathrm{Hg}$ (II) ion, respectively, with an unprecedented adsorption capacity $\left(q_{\mathrm{m}}\right)$ of $1667 \mathrm{mg} \mathrm{g}^{-1}$ and $1250 \mathrm{mg}$ $\mathrm{g}^{-1}$. This suggests that TSC-ZIFs possess both a high adsorption capacity and adsorption efficiency for the removal of mercury cations from water, in less than 2 hours and at ambient conditions (Fig. 4).

Adsorption isotherms for mercury(II) removal from water. The Langmuir (eqn (S3) and (S4) $\dagger$ ), and Freundlich (eqn (S5) $\dagger$ ) adsorption models were applied to analyse the obtained adsorption data for TSC-ZIFs. The experimental data fit well the Langmuir equilibrium adsorption isotherm with a correlation coefficient of $R^{2}>0.99$ (Fig. S18, $\dagger$ 4(b) and Table 3). However, the fitted Freundlich model resulted in a lower correlation coefficient $\left(R^{2}=0.92\right.$, Table $\left.\mathrm{S} 1 \dagger\right)$ indicating that the adsorption process, follows a spontaneous single-layer chemical adsorption. ${ }^{67,81}$

The maximum adsorption capacities of ZIFs reported in this study are presented in Table 3 . The separation factor $\left(R_{\mathrm{L}}\right)$ was calculated to be between 0 and 1 , indicating favourable adsorption of mercury cations into the prepared ZIFs (see Table 3). This can be attributed to the soft sulfur donor atoms incorporated in two different ratios within the pores of ZIF structures. In particular, the incorporation of bisthiosemicarbazone and thiosemicarbazone containing groups enhances mercury extraction performance with respect to the parent ZIF8. Adsorption capacity of $\mathbf{M I M}_{3.5}:$ Thio $_{1}: \mathbf{Z n}$ exceeds the values

Table 3 Langmuir adsorption isotherm fitting parameters for ZIF-8, Ald-ZIFs and TSC-ZIFs

Langmuir adsorption model parameters

\begin{tabular}{lllll}
\hline Samples & $K_{\mathrm{L}}\left(\mathrm{L} \mathrm{mg}^{-1}\right)$ & $R_{\mathrm{L}}$ & $q_{\mathrm{m}}\left(\mathrm{mg} \mathrm{g}^{-1}\right)$ & $R^{2}$ \\
\hline ZIF-8 & 0.019 & 0.38 & 3 & 0.9995 \\
MIM $_{15}:$ AldIM $_{1}: Z n$ & 0.036 & 0.2 & 13.4 & 0.9943 \\
MIM $_{15}:$ Bisthio $_{\mathbf{1}}: Z n$ & 0.59 & 0.017 & 128 & 0.9961 \\
MIM $_{15}:$ Thio $_{\mathbf{1}}: Z n$ & 0.15 & 0.062 & 152 & 0.9969 \\
MIM $_{3.5}:$ :ldIM $_{\mathbf{1}}: Z n$ & 0.052 & 0.15 & 124 & 0.9934 \\
MIM $_{3.5}:$ Bisthio $_{1}: Z n$ & 0.053 & 0.02 & 1250 & 0.9987 \\
MIM $_{3.5}:$ Thio $_{\mathbf{1}}: Z n$ & 0.013 & 0.07 & $\mathbf{1 6 6 7}$ & 0.9962
\end{tabular}

recently reported for porous functionalized ZIFs (see Table 1). ${ }^{64,65,67,68}$

Adsorption kinetics. In order to evaluate the kinetic mechanism controlling the adsorption process, the effect of contact time between $\mathrm{Hg}(\mathrm{II})$ and the adsorbents on the adsorption process was investigated.

The kinetic data were successfully fitted (Fig. S19 and S20†) to the pseudo-second-order kinetic model (eqn (S6) $\dagger$ ), as indicated by the high correlation coefficient values $\left(R^{2}>0.99\right.$ for ZIF8, MIM MId $_{\text {AldM }}: Z n$, MIM $_{15}:$ Bisthio $_{1}: Z n$, MIM $_{3.5}:$ AldIM $_{1}: Z n$, MIM $_{3.5}:$ Bisthio $_{1}: Z n$ and $R^{2}=1$ for MIM $_{15}:$ Thio $_{1}: Z n$, MIM $_{15}$ :Thio $:$ Zn). Adsorption rate constants $k_{2}$ at room temperature and neutral $\mathrm{pH}$ were determined to be $0.000059<0.00055<$ $0.0032 \mathrm{~g} \mathrm{mg}^{-1} \mathrm{~min}^{-1}$ for MIM $_{3.5}:$ AldIM $_{1}: Z n$, MIM $_{3.5}:$ Bisthio $_{1}: Z n$ and $\mathbf{M I M}_{3.5}:$ Thio $_{1}: \mathbf{Z n}$ respectively (Table S2 $\dagger$ ).

The adsorption rate constant $\left(k_{2}=0.32 \times 10^{-2} \mathrm{~g}\right.$ $\mathrm{mg}^{-1} \min ^{-1}$ ) of $\mathbf{M I M}_{3.5}:$ Thio $_{1}: \mathbf{Z n}$ exceeds many other reported porous absorbents in the literature. ${ }^{65}$ This can be attributed to the higher degree of thiosemicarbazone incorporation. The steric demands of the thiosemicarbazone group occupying the inner surface of the pores and the high density of $\mathbf{M I M}_{3.5}$ :Thio $\mathbf{1}_{\mathbf{1}} \mathbf{Z n}$ adsorption sites give this TSC-ZIF the best performance.

Characterisation of TSC-ZIFs after removal of mercury(II). PXRD patterns of $\mathbf{M I M}_{3.5}:$ Thio $_{1}: \mathbf{Z n}$ did not change after the adsorption of $\mathrm{Hg}$ (II) (Fig. 6(b)). The co-existence of $\mathrm{Hg}$ (II) with the TSC-ZIFs is observed in SEM images (Fig. S21†) and EDX analysis (Fig. S22 $)$ ). Similarly, TGA measurements of the $\mathrm{Hg}$ (II) adsorbed onto MIM $_{3.5}$ :Thio 1 :Zn show one mass loss step at about $350{ }^{\circ} \mathrm{C}$. This temperature is higher than that observed for MIM $_{3.5}$ :Thio 1 :Zn, confirming that the adsorbent maintained a stable framework structure after the adsorption process (Fig. S23†).

Competitive binding (binary and tertiary systems). To evaluate the selectivity of $\mathbf{M I M}_{3.5}$ : Thio $_{1}: \mathbf{Z n}$ for $\mathrm{Hg}$ (II) ion adsorption, we performed experiments in the presence of $\mathrm{Pb}$ (II) and $\mathrm{Cd}$ (II) as potential interfering species.

Binary adsorption with $\mathbf{P b}(\mathrm{II})$. Binary metal containing systems were prepared using a fixed concentration of $[\mathrm{Pb}(\mathrm{II})]=$ $1000 \mathrm{mg} \mathrm{L}^{-1}$ and a mercury concentration $[\mathrm{Hg}(\mathrm{II})]$ ranging from 100 to $400 \mathrm{mg} \mathrm{L}^{-1}$. The percentage removal of both metal ions,
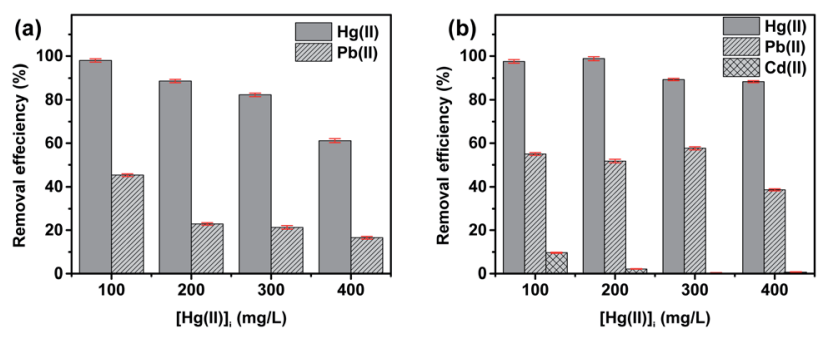

Fig. 5 (a) Mercury(II) adsorption onto MIM $_{3.5}:$ Thio $_{1}: Z n$, binary system with $[\mathrm{Pb}(॥)] /[\mathrm{Hg}(॥)]_{i}$ range: $100-400 \mathrm{mg} \mathrm{L}^{-1}$ and the initial $[\mathrm{Pb}(॥)]=$ $1000 \mathrm{mg} \mathrm{L}^{-1}$ in all samples tested, (b) mercury(॥) adsorption onto MIM $_{3.5}:$ Thio $_{1}: Z n$ in tertiary system with lead(॥) and cadmium(॥)/[Hg(॥)] range: $100-400 \mathrm{mg} \mathrm{L}^{-1}$ and the initial $[\mathrm{Pb}(॥)]_{\mathrm{i}}=[\mathrm{Cd}(॥)]_{\mathrm{i}}=1000 \mathrm{mg} \mathrm{L}^{-1}$ in all samples tested. 
existing in the binary system, is presented in Fig. 5(a). As depicted in the figure, $\mathbf{M I M}_{3.5}$ :Thio $\mathbf{T}_{1}: \mathbf{Z n}$ exhibits high removal efficiency for $\mathrm{Hg}$ (II) and low removal for $\mathrm{Pb}$ (II) ions, demonstrating a higher selectivity for $\mathrm{Hg}$ (II). Meanwhile, at higher mercury cations concentration, a co-adsorption induces a decrease in its adsorption. Previous studies have explained the removal of the metal ions in the competitive adsorption system is based on the comparative assessment of their initial adsorption rates. ${ }^{\mathbf{8 2 , 8 3}}$

Tertiary system with $\mathbf{P b}(\mathrm{II})$ and $\mathrm{Cd}(\mathrm{II})$. The concentration of $\mathrm{Pb}$ (II) and $\mathrm{Cd}$ (II) ions in the mixed solution was set each to $1000 \mathrm{mg} \mathrm{L}^{-1}$ and the $[\mathrm{Hg}(\mathrm{II})]$ ranging from 100 to $400 \mathrm{mg} \mathrm{L}^{-1}$. As illustrated in Fig. 5(b), interference of the two metal ions minimally disturbs the removal efficiency for $\mathrm{Hg}$ (II) ions, given that MIM $_{3.5}$ :Thio ${ }_{1}: \mathbf{Z n}$ exhibits lower removal efficiency towards $\mathrm{Cd}(\mathrm{II})$ and $\mathrm{Pb}$ (II) ions. Analysis of the removal efficiency values revealed that the order of adsorption was $\mathrm{Hg}$ (II) $>\mathrm{Pb}$ (II) $\gg$ $\mathrm{Cd}(\mathrm{II})$. Removal efficiency for $\mathrm{Cd}$ (II) and $\mathrm{Pb}$ (II) decreases when the concentration of $[\mathrm{Hg}$ (II) $]$ increases, which demonstrates the selective adsorption for $\mathrm{Hg}$ (II). Besides, the presence of $\mathrm{Cd}(\mathrm{II})$ in the tertiary solution enhanced the removal efficiency for $\mathrm{Hg}$ (II) and $\mathrm{Pb}$ (II) (Fig. 5(b)).

This selective adsorption for $\mathrm{Hg}$ (II) ions can be attributed to the higher affinity of thiosemicarbazone groups for $\mathrm{Hg}$ (II) compared to other metal ions. ${ }^{67}$

Regeneration of MIM $_{3.5}:$ Thio $_{1}: Z n$. In actual applications, reusability of adsorbents is crucial and reflects on the sustainability of the developed adsorbent. The reusability of $\mathbf{M I M}_{3.5}$ :Thio $_{1}$ :Zn was assessed through cycles of regeneration of the ZIF in solution using $p$-toluene sulfonic acid $(\mathrm{pH}=4)$ as a desorbent. Inspired by the literature, acidic conditions are expected to weaken the interaction between the adsorbate and adsorbent allowing for the regeneration of the TSC-ZIF. ${ }^{68}$ The relative efficiency of the removal of $\mathrm{Hg}$ (II) in each through cycles of adsorption-desorption of mercury by $\mathbf{M I M}_{3.5}: \mathbf{T h i o}_{1}: \mathbf{Z n}$ are presented in Fig. 6(a).

Over the five cycles, the amounts of mercury adsorbed decreased slightly with increasing the number of cycles, which might be caused by the loss of material during the recycling process. However, the adsorption efficiency was maintained at approximately $75 \%$ for the highest concentration of mercury(II)/ $\left([\mathrm{Hg}(\mathrm{II})]_{\mathrm{i}}=700 \mathrm{ppm}\right)$ of each cycle, indicating that $\mathbf{M I M}_{3.5}$ :- $^{-}$ Thio $_{1}: \mathbf{Z n}$ can be regenerated for cycles of mercury removal
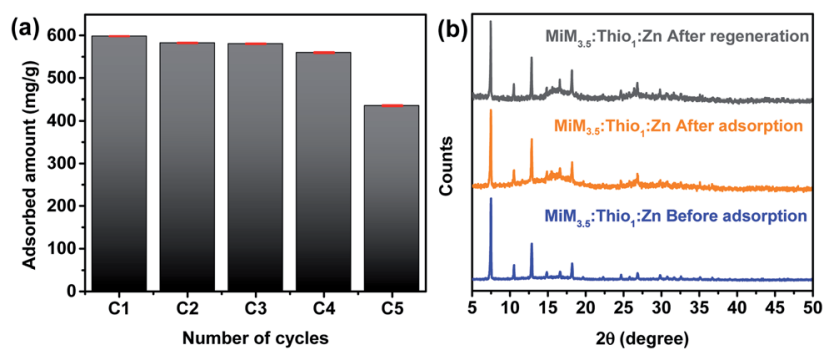

Fig. 6 (a) Reusability of MIM $_{3.5}:$ Thio $_{1}: Z n$ for the adsorbed amount of $\mathrm{Hg}\left({ }^{\prime \prime}\right)\left([\mathrm{Hg}(॥)]_{i}=700 \mathrm{ppm}\right)$ and (b) PXRD patterns of the MIM 3.5 $_{\text {:Thio }}: \mathrm{Zn}$ recorded before and after the adsorption of $\mathrm{Hg}(॥)$, and after the regeneration. without compromising its removal efficiency. PXRD patterns of the recycled MIM $_{3.5}:$ Thio $_{1}: \mathbf{Z n}$ (after the five cycle) were in good agreement with their PXRD patterns before adsorption (Fig. 6(b)). This demonstrates the high stability of the TSC-ZIF after the removal of mercury.

\section{Conclusions}

A new class of aldehyde-based zeolitic imidazolate frameworks (Ald-ZIF) was developed to serve as a precursor, which can be modified for the removal of mercury cations from water. Bisthiosemicarbazone and thiosemicarbazone are the functional groups introduced, through post-synthetic modification, to the new class of Ald-ZIF resulting in the formation of four classes of TSC-ZIF derivatives. TSC-ZIF contain pendent thiosemicarbazone groups within the pores of the material. The degree of functionalization of Ald-ZIF was monitored using IR and NMR spectroscopies. Structural and thermal integrity of the TSC-ZIF were confirmed using PXRD studies, SEM-EDX and TGA analysis. The porosity of the TSC-ZIF derivatives (as measured using BET surface area calculations) are reduced relative to $\mathbf{Z I F - 8}$, depending on the degree of functionalization and size of introduced substituents. Sequestration of mercury(II) from water at room temperature and neutral $\mathrm{pH}$ was achieved when treating $\mathrm{Hg}$ (II) contaminated water with TSC-ZIF derivatives. Among TSC-ZIF derivatives, MIM 3.5 $_{\mathbf{2}}$ :Thio $\mathbf{1}_{\mathbf{1}}: \mathbf{Z n}$ showed the highest capacity for mercury(II) ions due to the higher ratio of pore functionality, combined with the lower steric demands of the TSC group. Moreover, MIM $\mathbf{M}_{3.5}:$ Thio $_{1}: \mathbf{Z n}$ showed selectivity for $\mathrm{Hg}$ (II) in solutions containing competitive $\mathrm{Pb}$ (II) and $\mathrm{Cd}(\mathrm{II})$ metal ions. MIM $_{3.5}:$ Thio $_{1}: \mathbf{Z n}$ was regenerated for up to four cycles of mercury(II) removal without compromising the efficiency or structure of the ZIF. Therefore, TSCZIFs, as a new class of zeolitic frameworks, demonstrate promising adsorption capacity for heavy metals. Further work may provide a plethora of opportunities for generating new functionalized materials for other heavy metals and anions adsorption.

\section{Conflicts of interest}

There are no conflicts to declare.

\section{Acknowledgements}

This study was funded by the University Research Board (URB) of the American University of Beirut (AUB). This support is gratefully acknowledged. R. A. B. also acknowledges the K. Shair Central Research Science Laboratory (CRSL) at AUB for providing the facilities to carry out this work. C. P.-I. thanks Centro de Supercomputación de Galicia (CESGA), for providing the computer facilities.

\section{Notes and references}

1 Y. Peng, H. Huang, Y. Zhang, C. Kang, S. Chen, L. Song, D. Liu and C. Zhong, Nat. Commun., 2018, 9, 187. 
2 J. R. Bour, A. M. Wright, X. He and M. Dincă, Chem. Sci., 2020, 11, 1728-1737.

3 J. Hou, A. F. Sapnik and T. D. Bennett, Chem. Sci., 2020, 11, 310-323.

4 L. R. Redfern and O. K. Farha, Chem. Sci., 2019, 10, 1066610679.

5 Z. Su, Y.-R. Miao, G. Zhang, J. T. Miller and K. S. Suslick, Chem. Sci., 2017, 8, 8004-8011.

6 S. B. Kalidindi, S. Nayak, M. E. Briggs, S. Jansat, A. P. Katsoulidis, G. J. Miller, J. E. Warren, D. Antypov, F. Corà, B. Slater, M. R. Prestly, C. Martí-Gastaldo and M. J. Rosseinsky, Angew. Chem., Int. Ed., 2015, 54, 221-226.

7 N. Stock and S. Biswas, Chem. Rev., 2012, 112, 933-969.

8 R. C. Klet, T. C. Wang, L. E. Fernandez, D. G. Truhlar, J. T. Hupp and O. K. Farha, Chem. Mater., 2016, 28, 12131219.

9 A. J. Howarth, Y. Liu, P. Li, Z. Li, T. C. Wang, J. T. Hupp and O. K. Farha, Nat. Rev. Mater., 2016, 1, 1-15.

10 K. Koh, A. G. Wong-Foy and A. J. Matzger, J. Am. Chem. Soc., 2009, 131, 4184-4185.

11 O. K. Farha, I. Eryazici, N. C. Jeong, B. G. Hauser, C. E. Wilmer, A. A. Sarjeant, R. Q. Snurr, S. T. Nguyen, A. Ö. Yazaydın and J. T. Hupp, J. Am. Chem. Soc., 2012, 134, 15016-15021.

12 N. Cheng, L. Ren, X. Xu, Y. Du and S. X. Dou, Adv. Energy Mater., 2018, 8, 1801257.

13 T. A. Goetjen, J. Liu, Y. Wu, J. Sui, X. Zhang, J. T. Hupp and O. K. Farha, Chem. Commun., 2020, 56, 10409-10418.

14 K. Otake, Y. Cui, C. T. Buru, Z. Li, J. T. Hupp and O. K. Farha, J. Am. Chem. Soc., 2018, 140, 8652-8656.

15 F. Carraro, K. Chapman, Z. Chen, M. Dincă, T. Easun, M. Eddaoudi, O. Farha, R. Forgan, L. Gagliardi, F. Haase, D. Harris, S. Kitagawa, J. Knichal, C. Lamberti, J.-S. M. Lee, K. Leus, J. Li, W. Lin, G. Lloyd, J. R. Long, C. Lu, S. Ma, L. McHugh, J. P. H. Perez, M. Ranocchiari, N. Rosi, M. Rosseinsky, M. R. Ryder, V. Ting, M. van der Veen, P. V. D. Voort, D. Volkmer, A. Walsh, D. Woods and O. M. Yaghi, Faraday Discuss., 2017, 201, 369-394.

16 E. M. Miner, L. Wang and M. Dincă, Chem. Sci., 2018, 9, 6286-6291.

17 Z. Chang, R.-B. Lin, Y. Ye, C. Duan and B. Chen, J. Mater. Chem. A, 2019, 7, 25567-25572.

18 N. Scott Bobbitt, M. L. Mendonca, A. J. Howarth, T. Islamoglu, J. T. Hupp, O. K. Farha and R. Q. Snurr, Chem. Soc. Rev., 2017, 46, 3357-3385.

19 I. Abánades Lázaro and R. S. Forgan, Coord. Chem. Rev., 2019, 380, 230-259.

20 H. P. Veluswamy, A. Kumar, Y. Seo, J. D. Lee and P. Linga, Appl. Energy, 2018, 216, 262-285.

21 J.-H. Lee, R. L. Siegelman, L. Maserati, T. Rangel, B. A. Helms, J. R. Long and J. B. Neaton, Chem. Sci., 2018, 9, 5197-5206.

22 L. Wang, M. Zheng and Z. Xie, J. Mater. Chem. B, 2018, 6, 707-717.

23 M. Ibrahim, R. Sabouni and G. A. Husseini, Curr. Med. Chem., 2017, 24, 193-214.
24 M. Kotzabasaki and G. E. Froudakis, Inorg. Chem. Front., 2018, 5, 1255-1272.

25 H. Li, N. Lv, X. Li, B. Liu, J. Feng, X. Ren, T. Guo, D. Chen, J. F. Stoddart, R. Gref and J. Zhang, Nanoscale, 2017, 9, 7454-7463.

26 Y. Xie, X. Liu, X. Ma, Y. Duan, Y. Yao and Q. Cai, ACS Appl. Mater. Interfaces, 2018, 10, 13325-13332.

27 M. H. Teplensky, M. Fantham, P. Li, T. C. Wang, J. P. Mehta, L. J. Young, P. Z. Moghadam, J. T. Hupp, O. K. Farha, C. F. Kaminski and D. Fairen-Jimenez, J. Am. Chem. Soc., 2017, 139, 7522-7532.

28 Y. Chen, P. Li, J. A. Modica, R. J. Drout and O. K. Farha, J. Am. Chem. Soc., 2018, 140, 5678-5681.

29 E. A. Dolgopolova, A. M. Rice, C. R. Martin and N. B. Shustova, Chem. Soc. Rev., 2018, 47, 4710-4728.

30 Y.-P. Wu, G.-W. Xu, W.-W. Dong, J. Zhao, D.-S. Li, J. Zhang and X. Bu, Inorg. Chem., 2017, 56, 1402-1411.

31 S.-S. Zhao, J. Yang, Y.-Y. Liu and J.-F. Ma, Inorg. Chem., 2016, 55, 2261-2273.

32 P. A. Kobielska, A. J. Howarth, O. K. Farha and S. Nayak, Coord. Chem. Rev., 2018, 358, 92-107.

33 T. Islamoglu, S. Goswami, Z. Li, A. J. Howarth, O. K. Farha and J. T. Hupp, Acc. Chem. Res., 2017, 50, 805-813.

34 P. Deria, J. E. Mondloch, O. Karagiaridi, W. Bury, J. T. Hupp and O. K. Farha, Chem. Soc. Rev., 2014, 43, 5896-5912.

35 H.-F. Zhang, M. Li, X.-Z. Wang, D. Luo, Y.-F. Zhao, X.-P. Zhou and D. Li, J. Mater. Chem. A, 2018, 6, 4260-4265.

36 L. Garzón-Tovar, S. Rodríguez-Hermida, I. Imaz and D. Maspoch, J. Am. Chem. Soc., 2017, 139, 897-903.

37 S. M. Cohen, J. Am. Chem. Soc., 2017, 139, 2855-2863.

38 A. Singh, S. Karmakar, I. M. Abraham, D. Rambabu, D. Dave, R. Manjithaya and T. K. Maji, Inorg. Chem., 2020, 59, 82518258.

39 J. Li, X. Wang, G. Zhao, C. Chen, Z. Chai, A. Alsaedi, T. Hayat and X. Wang, Chem. Soc. Rev., 2018, 47, 2322-2356.

40 S. Dhaka, R. Kumar, A. Deep, M. B. Kurade, S. W. Ji and B. H. Jeon, Coord. Chem. Rev., 2019, 380, 330-352.

41 B. Chen, Z. Yang, Y. Zhu and Y. Xia, J. Mater. Chem. A, 2014, 2, 16811-16831.

42 G. Zhong, D. Liu and J. Zhang, J. Mater. Chem. A, 2018, 6, 1887-1899.

43 T. Wang, Y. Wang, M. Sun, A. Hanif, H. Wu, Q. Gu, Y. S. Ok, D. C. W. Tsang, J. Li, J. Yu and J. Shang, Chem. Sci., 2020, 11, 6670-6681.

44 Z. Hu, Y. Peng, Z. Kang, Y. Qian and D. Zhao, Inorg. Chem., 2015, 54, 4862-4868.

45 B. Zhang, Y. Luo, K. Kanyuck, N. Saenz, K. Reed, P. Zavalij, J. Mowery and G. Bauchan, RSC Adv., 2018, 8, 33059-33064.

46 G. L. Denisov, P. V. Primakov, A. A. Korlyukov, V. V. Novikov and Yu. V. Nelyubina, Russ. J. Coord. Chem., 2019, 45, 836842.

47 H. Shayegan, G. A. M. Ali and V. Safarifard, ChemistrySelect, 2020, 5, 124-146.

48 Z. Fu, W. Guo, Z. Dang, Q. Hu, F. Wu, C. Feng, X. Zhao, W. Meng, B. Xing and J. P. Giesy, Environ. Sci. Technol., 2017, 51, 3117-3118. 
49 W. Liang, M. Li, Z. Zhang, Y. Jiang, M. K. Awasthi, S. Jiang and R. Li, Int. J. Biol. Macromol., 2018, 113, 106-115.

50 Y. Zhu, Y. Zheng, W. Wang and A. Wang, J. Water Process Eng., 2015, 7, 218-226.

51 H. Borji, G. M. Ayoub, R. Bilbeisi, N. Nassar and L. Malaeb, Water. Air. Soil Pollut., 2020, 231, 330.

52 S. Bolisetty, M. Peydayesh and R. Mezzenga, Chem. Soc. Rev., 2019, 48, 463-487.

53 M. Xia, Z. Chen, Y. Li, C. Li, N. M. Ahmad, W. A. Cheema and S. Zhu, RSC Adv., 2019, 9, 20941-20953.

54 P. Kumar, A. Pournara, K.-H. Kim, V. Bansal, S. Rapti and M. J. Manos, Prog. Mater. Sci., 2017, 86, 25-74.

55 C. Tunsu and B. Wickman, Nat. Commun., 2018, 9, 4876.

56 M. K. O. Bengtsson, C. Tunsu and B. Wickman, Ind. Eng. Chem. Res., 2019, 58, 9166-9172.

57 J. Li, Y. Liu, Y. Ai, A. Alsaedi, T. Hayat and X. Wang, Chem. Eng. J., 2018, 354, 790-801.

58 K. Abbas, H. Znad and Md. R. Awual, Chem. Eng. J., 2018, 334, 432-443.

59 P. Samyn, A. Barhoum, T. Öhlund and A. Dufresne, J. Mater. Sci., 2018, 53, 146-184.

60 A. Oehmen, D. Vergel, J. Fradinho, M. A. M. Reis, J. G. Crespo and S. Velizarov, J. Hazard. Mater., 2014, 264, 65-70.

61 K.-K. Yee, N. Reimer, J. Liu, S.-Y. Cheng, S.-M. Yiu, J. Weber, N. Stock and Z. Xu, J. Am. Chem. Soc., 2013, 135, 7795-7798.

62 F. Ke, L.-G. Qiu, Y.-P. Yuan, F.-M. Peng, X. Jiang, A.-J. Xie, Y.-H. Shen and J.-F. Zhu, J. Hazard. Mater., 2011, 196, 36-43.

63 J. He, K.-K. Yee, Z. Xu, M. Zeller, A. D. Hunter, S. S.-Y. Chui and C.-M. Che, Chem. Mater., 2011, 23, 2940-2947.

64 S. Bhattacharjee, Y.-R. Lee and W.-S. Ahn, CrystEngComm, 2015, 17, 2575-2582.

65 H. Saleem, U. Rafique and R. P. Davies, Microporous Mesoporous Mater., 2016, 221, 238-244.

66 L. Liang, Q. Chen, F. Jiang, D. Yuan, J. Qian, G. Lv, H. Xue, L. Liu, H.-L. Jiang and M. Hong, J. Mater. Chem. A, 2016, 4, 15370-15374.

67 P. Yang, Y. Shu, Q. Zhuang, Y. Li and J. Gu, Chem. Commun., 2019, 55, 12972-12975.

68 F. Liu, W. Xiong, X. Feng, L. Shi, D. Chen and Y. Zhang, J. Hazard. Mater., 2019, 367, 381-389.

69 M. Jian, B. Liu, R. Liu, J. Qu, H. Wang and X. Zhang, RSC Adv., 2015, 5, 48433-48441.

70 A. Jaafar, A. Fix-Tailler, N. Mansour, M. Allain, W. N. Shebaby, W. H. Faour, S. Tokajian, A. El-Ghayoury, D. Naoufal, J.-P. Bouchara, G. Larcher and G. Ibrahim, Appl. Organomet. Chem., 2020, 34, e5988.

71 S. A. Andres, K. Bajaj, N. S. Vishnosky, M. A. Peterson, M. S. Mashuta, R. M. Buchanan, P. J. Bates and C. A. Grapperhaus, Inorg. Chem., 2020, 59, 4924-4935.
72 A. B. M. Ibrahim, M. K. Farh and P. Mayer, Inorg. Chem. Commun., 2018, 94, 127-132.

73 E. Ramachandran, V. Gandin, R. Bertani, P. Sgarbossa, K. Natarajan, N. S. P. Bhuvanesh, A. Venzo, A. Zoleo, M. Mozzon, A. Dolmella, A. Albinati, C. Castellano, N. Reis Conceição, M. F. C. Guedes da Silva and C. Marzano, Molecules, 2020, 25, 1868.

74 A. Sankaraperumal, A. N. Shetty and J. Karthikeyan, Synth. React. Inorg., Met.-Org., Nano-Met. Chem., 2015, 45, 13181326.

75 J. Chu, F.-S. Ke, Y. Wang, X. Feng, W. Chen, X. Ai, H. Yang and Y. Cao, Commun. Chem., 2020, 3, 1-7.

76 M. Kim, J. F. Cahill, H. Fei, K. A. Prather and S. M. Cohen, J. Am. Chem. Soc., 2012, 134, 18082-18088.

77 A. D. Becke, J. Chem. Phys., 1993, 98, 5648-5652.

78 M. J. Frisch, G. W. Trucks, H. B. Schlegel, G. E. Scuseria, M. A. Robb, J. R. Cheeseman, G. Scalmani, V. Barone, G. A. Petersson, H. Nakatsuji, X. Li, M. Caricato, A. Marenich, J. Bloino, B. G. Janesko, R. Gomperts, B. Mennucci, H. P. Hratchian, J. V. Ortiz, A. F. Izmaylov, J. L. Sonnenberg, D. Williams-Young, F. Ding, F. Lipparini, F. Egidi, J. Goings, B. Peng, A. Petrone, T. Henderson, D. Ranasinghe, V. G. Zakrzewski, J. Gao, N. Rega, G. Zheng, W. Liang, M. Hada, M. Ehara, K. Toyota, R. Fukuda, J. Hasegawa, M. Ishida, T. Nakajima, Y. Honda, O. Kitao, H. Nakai, T. Vreven, K. Throssell, J. A. Montgomery Jr, J. E. Peralta, F. Ogliaro, M. Bearpark, J. J. Heyd, E. Brothers, K. N. Kudin, V. N. Staroverov, T. Keith, R. Kobayashi, J. Normand, K. Raghavachari, A. Rendell, J. C. Burant, S. S. Iyengar, J. Tomasi, M. Cossi, J. M. Millam, M. Klene, C. Adamo, R. Cammi, J. W. Ochterski, R. L. Martin, K. Morokuma, O. Farkas, J. B. Foresman, and D. J. Fox, Gaussian 09, Revision E.01, Gaussian, Inc., Wallingford CT, 2016.

79 C. Lee, W. Yang and R. G. Parr, Phys. Rev. B, 1988, 37, 785789.

80 A. Phan, C. J. Doonan, F. J. Uribe-Romo, C. B. Knobler, M. O'Keeffe and O. M. Yaghi, Acc. Chem. Res., 2010, 43, 5867.

81 M. E. Mahmoud, M. F. Amira, S. M. Seleim and A. K. Mohamed, J. Chem. Eng. Data, 2017, 62, 839-850.

82 A. B. Duwiejuah, S. J. Cobbina, A. K. Quainoo, A. H. Abubakari and N. Bakobie, J. Health Pollut., 2018, 8, 180602-180614.

83 O. A. Adelaja, A. C. Bankole, M. E. Oladipo and D. B. Lene, Int. J. Energy Water Resour., 2019, 3, 1-12. 